\title{
New Material for Shields in X-Ray Diagnostic Procedures
}

\author{
Maria Anna Staniszewska ${ }^{1}$, Marian Zaborski ${ }^{2}$, Edyta Kusiak ${ }^{2}$ and Piotr Pankowski ${ }^{3}$ \\ 1. Department of Medical Imaging Techniques, Medical University of Lodz, Lindley Street 6, Lodz, 90-131, Poland \\ 2. Institute of Polymer \& Dye Technology, Technical University of Lodz, Stefanowski Street 12/16, Lodz, 90-924, Poland \\ 3. National Centre For Radiation Protection In Health Care, Smugowa Street 6, Lodz 91-433, Poland
}

\begin{abstract}
Shielding with the use of materials strongly absorbing X-rays is one of the oldest methods reducing patients' exposure to radiation. This article presents the results of the research aimed at developing a material, which will reduce radiation dose more efficiently than the materials produced so far, and will not change features of the computed tomography (CT) image. The current study focuses on elastomeric composites containing bismuth, wolfram, and gadolinium as the elements strongly absorbing X-rays in the range of energies used in diagnostic radiography. The aim of the study was to evaluate the effect of the made shields on the quality of CT image and properties reducing radiation. Measurements with the use of dosimetry phantoms have proven that the impact of shields on the distribution of energy absorbed in the inside of the object is limited to the regions situated directly under the shield surface. The material containing bismuth, wolfram and gadolinium most efficiently reduced doses measured in the BODY phantom. Hence, real shield efficacy was verified by measuring dose distribution on the surface of the phantom imitating a 5-year-old child (CIRS) and comparing the dose values registered without the shield and those achieved after using the shield. On the basis of the results achieved in the study was concluded that $50 \%$ attenuation of X-ray beam emitted by the CT scanner is available using the (Bi+W+Gd shield) and the effect of reduction of X-radiation intensity is visible in the surface layer of the exposed object located directly beneath the shield.
\end{abstract}

Key words: Computed tomography, patients, doses, shields, bismuth.

\section{Introduction}

The problem of shielding for patients subject to radiological procedures has been discussed again in recent years. Numerous studies [1-3] recommend using shields particularly in CT examination which is still regarded as a procedure causing considerable exposure of patients to X-rays.

Shielding with the use of materials strongly absorbing X-rays is one of the oldest methods reducing patients' exposure to radiation. Traditionally, lead rubber with the lead equivalent is used; the latter differs depending on energy and intensity of radiation, against which the shield is to protect patients. Due to lead toxicity and considerable weight of lead rubber shields, latex shields with the addition of bismuth as a basic radiation absorbent have appeared on the market.

This article presents the results of the research aimed

Corresponding author: Maria Anna Staniszewska, Ph.D., ass. prof., research fields: medical physicist, specialist of radiation protection. at developing a material, which will reduce radiation dose more efficiently than the materials produced so far, and will not change features of the computed tomography (CT) image. This technique of imaging has been selected as a subject of studies because of the relationship between the image composition and the energetic characteristics of $\mathrm{X}$ radiation, which does not occur in conventional planar techniques (with the exception of mammography). At the same time, taking into consideration a higher sensitivity of the child's body to induction of post-radiation effect, the experimental verification of the efficiency of shields was performed with the use of an anthropomorphic phantom imitating a 5-year-old child.

\section{Material and Methodology}

\subsection{Study Material}

The current study focuses on elastomeric composites containing bismuth, wolfram, and gadolinium as the elements strongly absorbing X-rays in the range of 
energies used in diagnostic radiography.

The choice of these elements has resulted from energetic characteristics of the mass attenuation coefficient, which is presented in Fig. 1.

Such properties of gadolinium and wolfram allow researchers to expect that shields containing these elements will not induce significant changes in the quality of radiographic images and will guarantee a considerable attenuation of primary X-ray beam. This will be of special significance for extreme spectral energies, and will preserve the primary course of the spectrum in the range of energies used to create the $\mathrm{X}$-ray images as opposed to bismuth shields alone.

Therefore, three types of composites were prepared which contained the following elements as an absorbent: (1) exclusively $\mathrm{Bi}_{2} \mathrm{O}_{3}$ in the amount of 50 phr, (2) 50 phr $\mathrm{Bi}_{2} \mathrm{O}_{3}+50 \mathrm{phr} \mathrm{WO}_{3}$, (3) $50 \mathrm{phr} \mathrm{Bi}_{2} \mathrm{O}_{3}+$ 50 phr $\mathrm{WO}_{3}+50$ phr $\mathrm{Gd}_{2} \mathrm{O}_{3}$.

India rubber was the elastomeric material. Fifty mass particles of absorbent radiation were added to 100 mass particles of India rubber. After adding necessary cross-linking agents, the material was subject to vulcanization process.

The mass attenuation coefficient was calculated for these composites as a linear combination of all input components taking into consideration their weight.

Attenuation of polychromatic primary X-ray beam caused by transition through the shield is expressed by the $\mathrm{K}=\mathrm{I} / \mathrm{I}_{\mathrm{o}}$ coefficient, where

$\mathrm{k}=\sum \mathrm{p}\left(\mathrm{E}_{\mathrm{i}}\right) \cdot \exp \left[-\mu / \rho\left(\mathrm{E}_{\mathrm{i}}\right) \cdot \rho \cdot \mathrm{x}\right]$

Values of $\mathrm{p}\left(\mathrm{E}_{\mathrm{i}}\right)$ expressing the probability of finding a photon of energy $E_{i}$ in the discussed spectrum were determined on the basis of the data from the spectrum catalogue [4].

Values of $\mu, \rho,(\mu / \rho)$ for the discussed elements and compounds were taken from the literature $[5,6]$. The parameters characterizing the composites are given in Table 1.

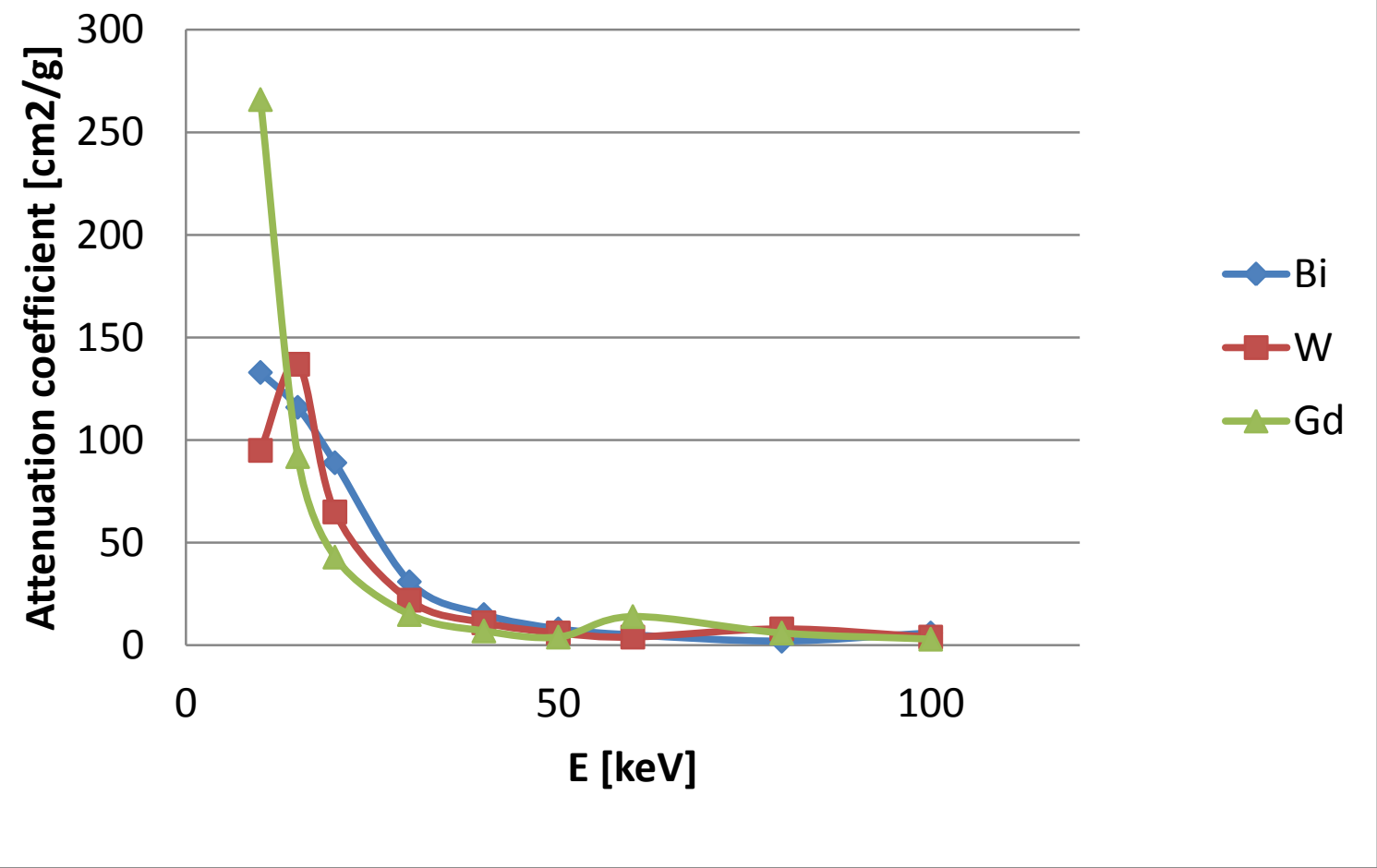

Fig. 1 The mass attenuation coefficient of bismuth, wolfram, and gadolinium versus energy [4]. 
Table 1 Calculated values of $\frac{\mu}{\rho}(E)$ and densities for the composites with the mixture of absorbents.

\begin{tabular}{lll}
\hline Composite & $\mu / \rho\left[\mathrm{cm}^{2} / \mathrm{g}\right]$ & $\rho\left[\mathrm{g} / \mathrm{cm}^{3}\right]$ \\
\hline $\mathrm{NR} / \mathrm{Bi}_{2} \mathrm{O}_{3}$ & 1.4 & 1.36 \\
$\mathrm{NR} / \mathrm{Bi}_{2} \mathrm{O}_{3} / \mathrm{WO}_{3}$ & 3.6 & 1.72 \\
$\mathrm{NR} / \mathrm{Bi}_{2} \mathrm{O}_{3} / \mathrm{WO}_{3} / \mathrm{Gd}_{2} \mathrm{O}_{3}$ & 3.4 & 2.01 \\
\hline
\end{tabular}

\subsection{Study Methods}

The X-radiation source was the 256-slice computed tomography (CT) scanner (iCT, Philips).

The aim of the study was to evaluate the effect of the made shields on: (1) the quality of CT image, (2) properties reducing radiation.

All the shields had the same thickness of $1 \mathrm{~mm}$.

Indices of the image quality TK were determined by using a multi-section Catphan 500 phantom (The Phantom Laboratory Incorporated, Salem, NY), assigned to control the quality of multi-slice/multiple row CT scanners.

The reduction in radiation was examined by measuring the distribution of DLP (Dose Lenght Product) values in a dosimetry cylindrical BODY phantom with a diameter $\emptyset=32 \mathrm{~cm}$. BODY phantom with the shield is presented on Fig. 2. A Barracuda dosimeter (RTI, Sweden) with a pencil-shaped ionization chamber was used for this purpose. The measurements were performed for three materials $(\mathrm{Bi}$, $\mathrm{Bi}+\mathrm{W}, \mathrm{Bi}+\mathrm{W}+\mathrm{Gd})$.

Measurements with the use of dosimetry phantoms have proven that the impact of shields on the distribution of energy absorbed in the inside of the object is limited to the regions situated directly under the shield surface. A dosimetry phantom is a homogeneous PMMA cylinder, while the human body is heterogeneous as regards the shape and the spatial distribution of density.

Hence, shield efficacy was verified by measuring dose distribution on the surface of the phantom imitating a 5-year-old child (CIRS) and comparing the dose values registered without the shield and those achieved after using the shield. The $\mathrm{Bi}+\mathrm{W}+\mathrm{Gd}$ shield most efficiently reduced DLP measured in the BODY phantom. A phantom imitating a 5-year-old child with the shield placed on its surface is presented on Fig. 3.

A thermoluminescent dosimeter of high sensitivity (MCP, LADIS Kraków) was used for measurements on the CIRS phantom.

The scanned region included the entire phantom height. Radiation exposure to the phantom included a pilot scan and one spiral scan using the following exposure parameters: $80 \mathrm{kV}, 150 \mathrm{mAs} / \mathrm{scan}$, pitch 0.398 (these parameters are used in the abdominal examination of children weighing from 10 to $30 \mathrm{~kg}$ ). The first exposure was performed without shielding, and next, the anterior part of the phantom surface was shielded, the automatic modulation of anode current intensity was switched off (for maintaining identical exposure parameters) and the phantom exposure was repeated. Obviously, each exposure was performed with a different set of TL dosimeters. The shield covered the anterior surface of the phantom between layers 19-25.

\section{Results}

The impact of shields on the quality of CT images is illustrated in Table 2.

The impact of shields on the radiation reduction evaluated on the dosimetry BODY phantom is demonstrated in Table 3.

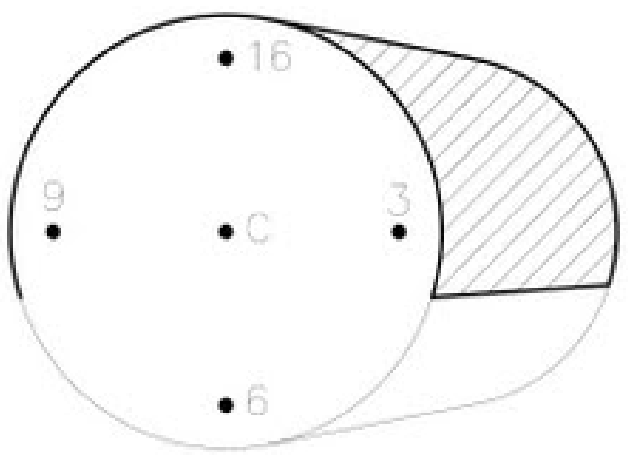

Fig. 2 Location of shields and measurement holes on the phantom during the exposure. 


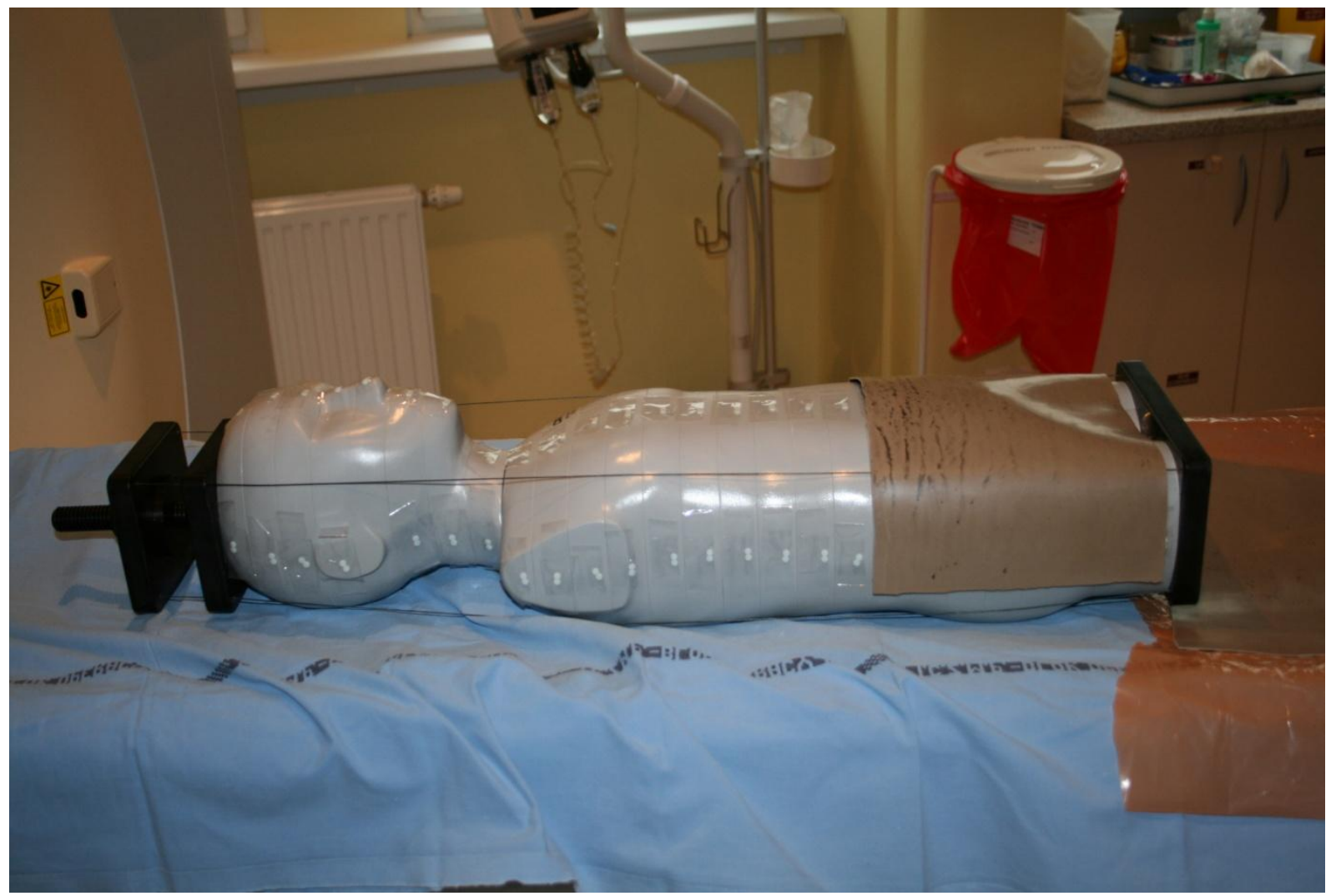

Fig. 3 A phantom imitating a 5-year-old child with the shield placed on its surface.

Table 2 Indices of the quality of Catphan phantom image (Spiral CT radiation exposure: $120 \mathrm{kV}, \mathrm{p}=0.993, \mathrm{I}=323$ mAs/scan).

\begin{tabular}{|c|c|c|c|c|c|c|}
\hline \multirow[b]{2}{*}{ Shield } & \multirow[b]{2}{*}{$\begin{array}{l}\mathrm{SC} \\
{[\mathrm{mm}]}\end{array}$} & \multirow[b]{2}{*}{ SNR } & \multicolumn{2}{|c|}{ Low-contrast objects } & \multirow[b]{2}{*}{$\begin{array}{l}\text { High-contrast } \\
\text { resolution } \\
{[\text { no./cm]; }} \\
(\text { gap size, } \mathrm{cm})\end{array}$} & \multirow[b]{2}{*}{$\begin{array}{l}\text { Sensitometric } \\
\text { Measurements } \\
{[\mathrm{HU} \pm \sigma \mathrm{HU}]}\end{array}$} \\
\hline & & & $\begin{array}{l}\text { Supra-slice } \\
d_{\min }(1 \%) \\
d_{\min }(0.5 \%) \\
d_{\min }(0.3 \%) \\
{[\mathrm{mm}]}\end{array}$ & $\begin{array}{l}\text { Sub-slice } \\
\mathrm{d}_{\min }(7 \mathrm{~mm}) \\
d_{\text {min }}(5 \mathrm{~mm}) \mathrm{d}_{\text {min }} \\
(3 \mathrm{~mm}) \\
{[\mathrm{mm}]}\end{array}$ & & \\
\hline No shield & 5 & 31.52 & $\begin{array}{l}2 \\
2 \\
2\end{array}$ & $\begin{array}{l}3 \\
3 \\
5\end{array}$ & $\begin{array}{l}6 ;(0.083) \\
{[9 *] ;\left(0.056^{*}\right)}\end{array}$ & $\begin{array}{l}\text { Air: }-950.2 \pm 88.1 \\
\text { Teflon: } 933.6 \pm 89.9 \\
\text { Acrylic: } 120.4 \pm 3.2 \\
\text { LDPE: }-87.8 \pm 11.2\end{array}$ \\
\hline $\mathrm{Bi}_{2} \mathrm{O}_{3}$ & 5 & 28.33 & $\begin{array}{l}2 \\
2 \\
2\end{array}$ & $\begin{array}{l}3 \\
3 \\
3\end{array}$ & $\begin{array}{l}6 ;(0.083) \\
{[9 *] ;\left(0.056^{*}\right)}\end{array}$ & $\begin{array}{l}\text { Air: }-952.8 \pm 73.8 \\
\text { Teflon: } 935.6 \pm 72.0 \\
\text { Acrylic: } 121.3 \pm 2.6 \\
\text { LDPE: }-86.7 \pm 15.2\end{array}$ \\
\hline $\mathrm{Bi}_{2} \mathrm{O}_{3}+\mathrm{WO}_{3}$ & 5 & 22.19 & $\begin{array}{l}2 \\
3 \\
3\end{array}$ & $\begin{array}{l}3 \\
5 \\
7\end{array}$ & $\begin{array}{l}6 ;(0.083) \\
{[9 *] ;\left(0.056^{*}\right)}\end{array}$ & $\begin{array}{l}\text { Air: }-926.4 \pm 76.5 \\
\text { Teflon: } 943.7 \pm 82.0 \\
\text { Acrylic: } 124.6 \pm 3.7 \\
\text { LDPE: }-75.9 \pm 13.8\end{array}$ \\
\hline $\mathrm{Bi}_{2} \mathrm{O}_{3}+\mathrm{WO}_{3}+\mathrm{Gd}_{2} \mathrm{O}_{3}$ & 5 & 18.74 & $\begin{array}{l}2 \\
4 \\
6\end{array}$ & $\begin{array}{l}3 \\
5 \\
7\end{array}$ & $\begin{array}{l}6 ;(0.083) \\
{[9 *] ;\left(0.056^{*}\right)}\end{array}$ & $\begin{array}{l}\text { Air: }-902.6 \pm 88.3 \\
\text { Teflon: } 959.2 \pm 66.6 \\
\text { Acrylic: } 128.8 \pm 3.2 \\
\text { LDPE: }-65.8 \pm 11.3\end{array}$ \\
\hline
\end{tabular}

The distribution of registered values of surface doses (more accurately-air kerma at the surface of the phantom imitating a 5-year-old child) for radiation exposure without a shield and with the $\mathrm{Bi}+\mathrm{W}+\mathrm{Gd}$ shield is presented in Figs. $4 \mathrm{~A}$ and $4 \mathrm{~B}$. 
Table 3 DLP [mGy.cm] values measured during scanning performed at the voltage of $120 \mathrm{kV}$ ( $\mathrm{spiral}, \mathrm{p}=0.993, \mathrm{I}=323$ $\mathrm{mAs} / \mathrm{scan}$ ); the length of the scanned segment was constant and equaled $15.5 \mathrm{~cm}$.

\begin{tabular}{llllll}
\hline \multirow{2}{*}{ Type of shield } & \multicolumn{4}{c}{ Place of measurement } \\
\cline { 2 - 6 } & "C" & "12" & "3" & "6" & "9" \\
\hline No shield & 154.0 & 308.1 & 261.9 & 207.9 & 269.6 \\
$50 \mathrm{Bi}_{2} \mathrm{O}_{3}$ & 138.6 & 223.3 & 277.3 & 223.3 & 277.3 \\
$50 \mathrm{Bi}_{2} \mathrm{O}_{3}+50 \mathrm{WO}_{4}$ & 130.9 & 200.2 & 285.0 & 207.9 & 269.6 \\
$50 \mathrm{Bi}_{2} \mathrm{O}_{3}+50 \mathrm{WO}_{4}+50 \mathrm{Gd}_{2} \mathrm{O}_{3}$ & 130.9 & 161.7 & 277.3 & 207.9 & 261.9 \\
\hline
\end{tabular}

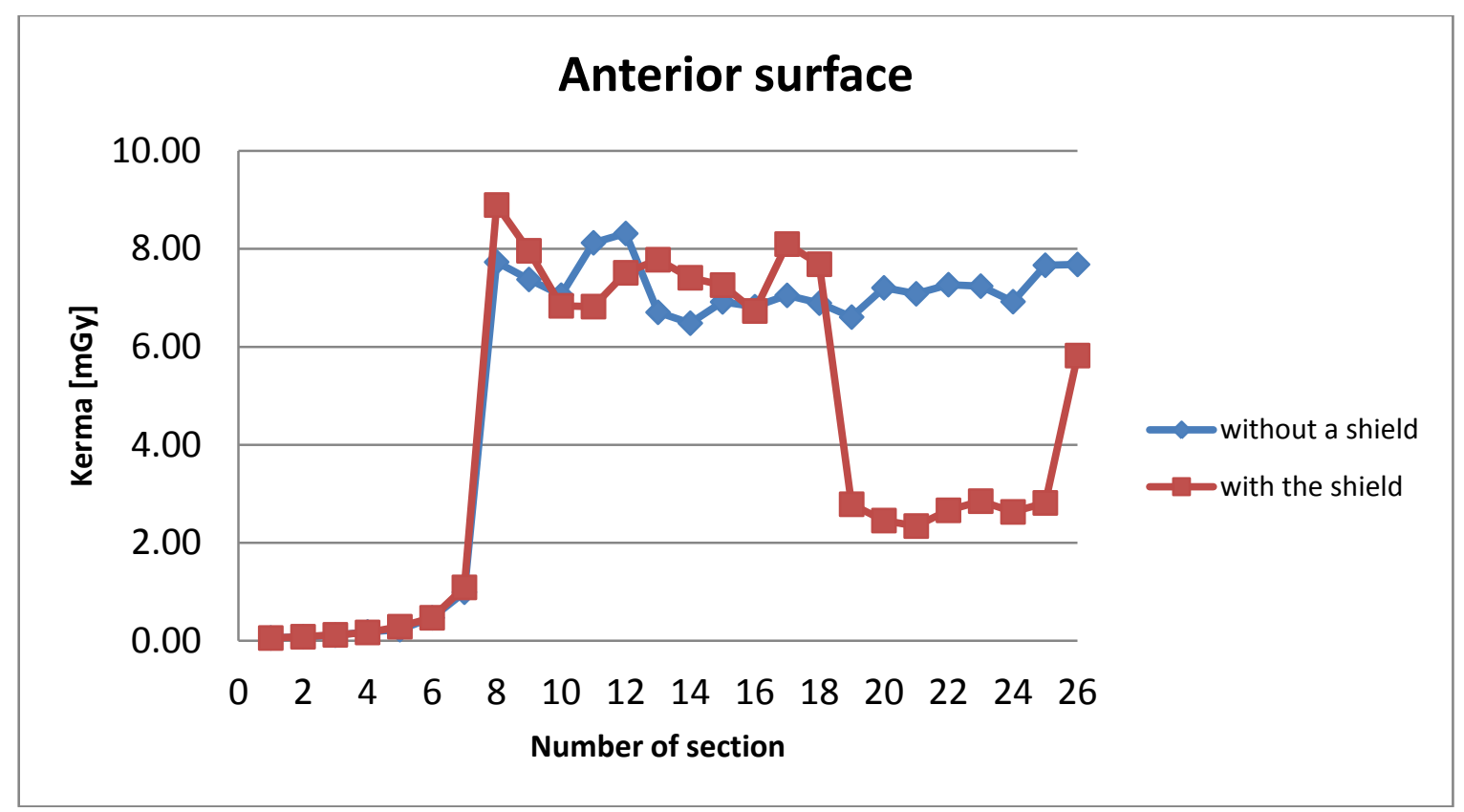

Fig. 4A The distribution of air kerma on the anterior surface of the phantom imitating a 5-year-old child.

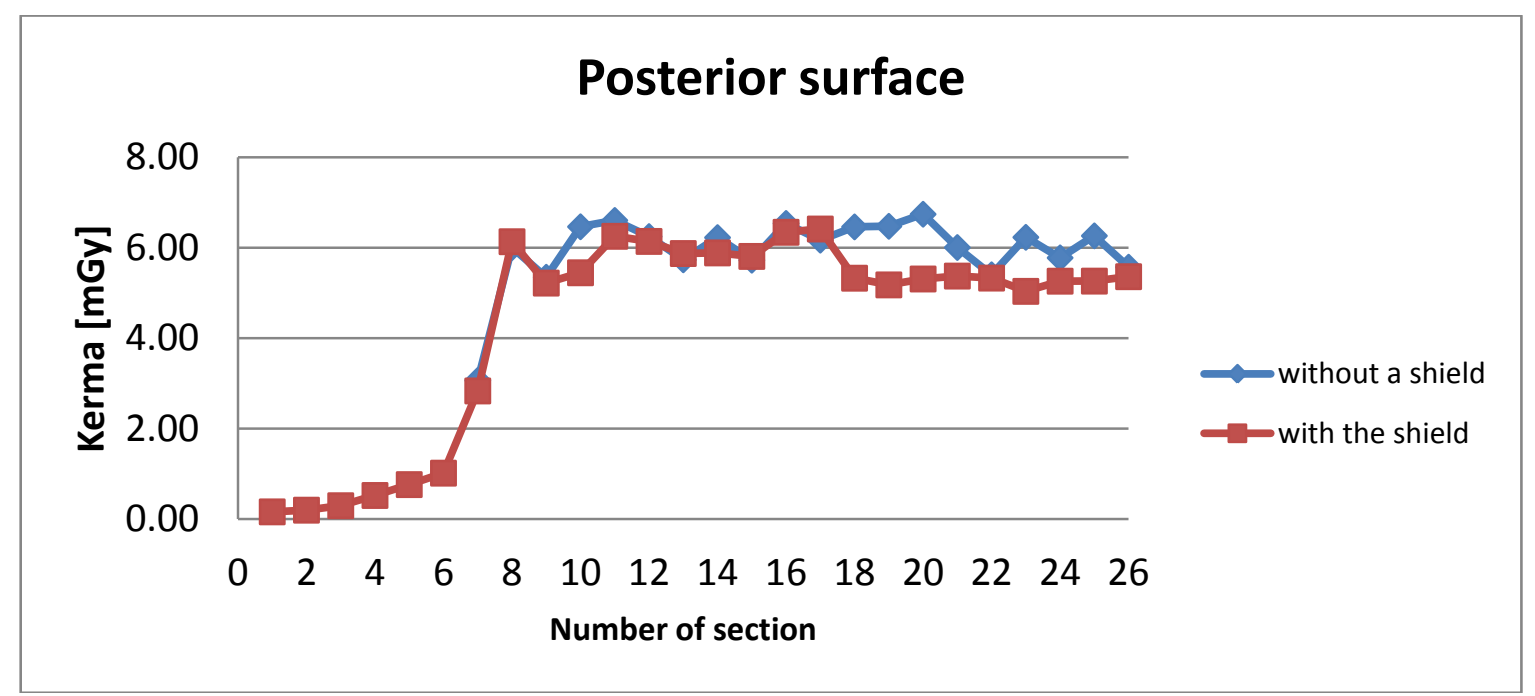

Fig. 4B The distribution of kerma in air on the posterior surface of the phantom imitating a 5-year-old child.

\section{Results and Discussion}

The use of shields, especially on organs sensitive to radiation, which are localized in the area subject to scanning, have been recommended in studies published in recent years. It usually concerns eyes in head 
examinations, and breasts and thyroid in chest and neck examinations. The study results are based on measurements performed on phantoms [7, 9], as well as on the data of patients exposed to radiation $[8,10]$, and they show $26 \%-42 \%$ of the dose reduction.

The material which those shields were made of was bismuth. However, shielding parameters were not accurately specified.

The general conclusion drawn from the literature data is as follows: the use of the Bi shield (probably with lead equivalent of at least $0.25 \mathrm{~mm}$ ) allows to reduce radiation dose by $30 \%-40 \%$ in organs/parts of body localized directly beneath the shield which are in the region of scanning.

This outcome is in compliance with the results of the present study in which: (1) $50 \%$ reduction in the dose was achieved owing to the shield containing $\mathrm{Bi}+\mathrm{W}+$ $\mathrm{Gd}$, (2) the reduction was checked on the child phantoms in the region of the abdominal cavity, in which organs significantly sensitive to radiation can be found.

It should be however emphasized that the kerma values registered on the anterior surface of the phantom imitating a 5-year-old child provide the evidence for the occurrence of "marginal effect" of the shield, which increases the kerma value in the close vicinity of the shield, just beyond its border (Fig. 4A). Great caution is necessary to use this type of method reducing radiation exposure! Using shields is particularly non-efficient, when automatic modulation of anode current intensity is applied. In such a case, a considerable increase in radiation intensity is observed in the area covered by a shield, which eliminates dose reduction for the patient, and additionally, needlessly overloads the CT scanner (accelerating its wear). Studies on this subject were published a few years ago (e.g. [11, 12]), and their outcomes are included in the AAPM recommendations of 2012 [13]. The use of automatic dose modulation or implementation of the iterative reconstruction of image data is much more efficient.
As mentioned in the Introduction to the present article, the use of shields is the oldest and the most frequently applied method of reducing radiation doses for patients. However, in the case of computed tomography, new methods of dose reduction are better. Excellent reducing properties of the discussed material $(\mathrm{Bi}+\mathrm{W}+\mathrm{Gd})$ can be sucessfully used during radiographic procedures with planar image registration.

\section{Conclusions}

On the basis of the results achieved in the study on properties and efficiency of the materials assigned for shielding the patients during $\mathrm{CT}$ examinations, the following conclusions can be drawn:

(1) $1 \mathrm{~mm}$ thickness of the material containing bismuth, wolfram and gadolinium allows to achieve 50\% attenuation of X-ray beam emitted by the CT scanner (at the voltage of $120 \mathrm{kV}$ ).

(2) Addition of gadolinium and wolfram improves the properties of the shield as compared to shields containing only bismuth.

(3) The effect of reduction of X-radiation intensity is visible in the surface layer of the phantom located directly beneath the shield.

(4) Due to the possibility of spreading radiation at the shield border, the shield should be situated beyond the scanning region.

(5) The presence of the shield in the scanning region affects discrimination of low-contrast objects as well as the level of the contrast for a model material corresponding to the soft tissue (sensitometry-LDPE).

\section{Acknowledgments}

This work was financially supported by the National Centre for Research and Development under grant No. NR05-0087-10/2010.

\section{References}

[1] Kim, S., Frush, D. P., and Yoshizumi, T. T. 2010. "Bismuth Shielding in CT: Support for Use in Children." Pediatric Radiology 40 (11): 1739-43. 
[2] Geleijns, J., Artells, M. S., Veldkamp, W. J., Tortosa, M. L., and Cantera, A. C. 2006. "Quantitative Assessment of Selective In-plane Shielding of Tissues in Computed Tomography through Evaluation of Absorbed Dose and Image Quality." European Radiology 16 (10): 2334-40.

[3] Vollmar, S. V., and Kalender, W. A. 2008. "Reduction of Dose to the Female Breast in Thoracic CT: A Comparison of Standard-protocol, Bismuth-Shielded, Partial and Tube-Current-Modulated CT Examinations." European Radiology 18 (8): 1674-82.

[4] Seelentag, W. W., Panzer, W., Drexler, G., Platz, L., and Santer, R. 1979. A Catalogue of Spectra for the Calibration of Dosemeters. Munchen, GSF- Bericht, 560.

[5] Nemec, O. F., and Gorman, Y. W. 1975. Vade-mecum of Nuclear Physics. Kijev: Naukova Dumka, 218-29. (in Russian)

[6] Hubbell, H. I. 1982. "Photon Mass Attenuation and Energy-absorption Coefficients from $1 \mathrm{keV}$ to $20 \mathrm{MeV}$." The International Journal of Applied Radiation and Isotopes 33 (11): 1269-90.

[7] Mukundan, S., Wang, P. I., Frush, D. P., Yoshizumi, T., Marcus, J., Kloeblen, E., and Moore, M. 2007. "MOSFET Dosimetry for Radiation Dose Assessment of Bismuth Shielding of the Eye in Children." American Journal of Radiology 188 (6): 1648-880.

[8] Fricke, B. L., Donnelly, L. F., Frush, D. P., Yoshizumi, T.,
Varchena, V., Poe, S. A., and Lucaya, J. 2003. "In-plane Bismuth Breast Shields for Pediatric CT: Effects on Radiation Dose and Image Quality Using Experimental and Clinical Data." American Journal of Radiology 180 (2): 407-11.

[9] Coursey, C., Frush, D. P., Yoshizumi, T., Yoshizumi, T., Toncheva, G., Nguyen, G., and Greenberg, S. B. 2008. "Pediatric Chest MDCT Using Tube Current Modulation: Effect on Radiation Dose with Breast Shielding." American Journal of Radiology 190 (1): W54-61.

[10] Persinakis, K., Raissaki, M.,Tzedakis, A., Teocharopoulos, N., Damilakis, J., and Gourtsoyannis, N. 2005. "Reduction of Eye Lens Radiation Dose by Orbital Bismuth Shielding in Pediatric Patients Undergoing CT of the Head: A Monte Carlo Study." Medical Physics 32 (4): 1024-30.

[11] Leswick, D. A., Hunt, M. M., Webster, S. T., and Fladeland, D. A. 2008. "Thyroid Shields versus Z-Axis Automatic Tube Current Modulation for Dose Reduction at Neck CT." Radiology 249 (2): 572-80.

[12] McCollugh, C. H., Wang, J., and Berland, L. L. 2011. "Bismuth Shields for CT Dose Reduction: Do They Help or Hurt?" Journal of the American College of Radiology 8 (12): 878-9.

[13] Statement Approved by AAPM Board of Directors. 2012. Policy number PP 26-A: "Use of Bismuth Shielding for the Purpose of Dose Reduction." Accessed February 7, 2012. http://www.aapm.org/org/policies/ 